\title{
Electrocardiographic Changes During Pregnancy at Third Trimester: A Comparative Study
}

\author{
Sonam Chaudhary ${ }^{1}$, Chanchhu Gopal Saha1, Dipali Sarkar ${ }^{1}$
}

${ }^{1}$ Manipal College of Medical Sciences, Pokhara, Nepal

\section{ABSTRACT}

Introduction: The cardiovascular system undergoes physiological changes during pregnancy. Electrocardiograms thereby play important role in understanding these physiological changes with the pathological one. The study has been carried out to study the electrocardiographic changes in pregnant women of third trimester and compare it with the non-pregnant women of same age group. Methods: Sixty third trimester pregnant women and sixty non-pregnant women of same age group attending Manipal Teaching Hospital were included. The 12 lead electrocardiograms of the participants were taken in supine position. The electrocardiograms were studied for various parameters like waves, intervals, segments and mean ventricular depolarization axis. Result: The result showed increase in heart rate in pregnant women when compared to control group. The decrease in PR interval associated with pregnancy was highly significant. The abnormalities in $\mathrm{T}$ wave associated with pregnancy, mostly in lead $\mathrm{V}_{1}, \mathrm{~V} 2, \mathrm{~V}_{3}$, $\mathrm{V}_{4}$, III and aVF were also highly significant. There was also increase occurrence of $\mathrm{Q}$ waves in pregnant women mostly in the bipolar leads. The QRS frontal axis compared to control showed increased tendency to shift towards left with advancing pregnancy. There was also significant increase in QT and QTc interval in third trimester pregnant women. The amplitude of various waves seemed to be decreased with pregnancy as well. Conclusion: This study shows that changes in electrocardiograms in third trimester pregnant women do occur. Therefore interpretation and evaluation of electrocardiograms in pregnancy should be done with caution.

Keywords: electrocardiogram; pregnancy; third trimester

\section{INTRODUCTION}

The effect of pregnancy on the electrocardiogram (ECG) has been a subject of great interest since the early days of electrocardiography. ${ }^{1}$ Large numbers of local and systemic changes occur and continue throughout pregnancy. ${ }^{2}$ This includes cardiovascular changes such as increase in heart rate, cardiac output and intravascular volume. ${ }^{3}$ These physiological changes facilitate the adaptation of the cardiovascular system to the increased metabolic needs of the mother enabling adequate delivery of oxygenated blood to the peripheral tissues and to the fetus. ${ }^{4}$

The alterations in cardiac activity implied by hormonal changes may cause increase in heart

Correspondence: Sonam Chaudhary, Department of Physiology, Manipal College of Medical Sciences, Pokhara, Nepal. Email: sunamch@gmail.com 
rate with increased atrioventricular conductivity. The anatomical increase in uterus size contributes to the shifting of main ventricular depolarization axis and similarly few myocardial ischemic changes of negligible magnitudes along with increase frequency of $\mathrm{Q}$ waves in chest leads have also been reported.

Understanding of these physiological changes is important to distinguish from pathological changes. ${ }^{5}$ With the aim of knowing the basis of physiological changes in ECG during pregnancy, the study was done between third $\left(3^{\text {rd }}\right)$ trimester pregnant women and normal non-pregnant women. The problem arises with the pathological mimicry of physiological changes before or during pregnancy. However, a simple ECG before pregnancy for every women would provide an opportunity not to diagnose heart disease when none exists and at the same time not to fail to detect and appropriately treat heart diseases when it does exist.

\section{METHODS}

This prospective cross sectional study was done in Manipal Teaching Hospital, Pokhara, between academic years 2012/2013 A.D under the permission granted from the ethical and research committee of the hospital. 60 pregnant women of $3^{\text {rd }}$ trimester as cases and 60 non-pregnant women as control between the age group of 20-35 years were included. Women with any organic cardiac disease, multiple pregnancies, renal disease, and thyroid disease or with diabetes, hypertension, chronic medication and past intra-thoracic surgery were excluded. The control group consists of age satisfying normal female volunteers. The electrocardiograms in 12 leads were interpreted in terms of waves, intervals, segments and QRS frontal axis. Each small box horizontally was calculated to be 0.04 seconds and each small box vertically was $0.1 \mathrm{mV}$ in electrocardiograms. The heart rate was calculated by dividing 1500 with number of small boxes between RR intervals. The QTc interval was determined using modified Bazett's formula by Hodges and co-workers. It corrects QT interval more completely for high and low heart rates. ${ }^{6}$

$\mathrm{QTc}=\mathrm{QT}+0.00175(\mathrm{HR}-60)$

The data were analyzed by SPSS-16 version. The independent T- test and Chi- Square tests were used to compare the association of ECG changes between two groups. $\mathrm{P}$ value was considered not significant if more than 0.05 , significant if less than 0.05 and highly significant if less than 0.001 . (* in tables)

\section{RESULTS}

In the present study the mean age of control and $3^{\text {rd }}$ trimester pregnant women was $24.75 \pm 3.51$ and $22.80 \pm 1.75$ years respectively. The ECG parameters comparisons showed that the decrease in PR interval duration, increase in QTc interval duration, decrease in mean frontal QRS axis and S wave amplitude were statistically significant in $3^{\text {rd }}$ trimester pregnant women when compared to control group. The rise in mean heart rate was calculated to be increased in pregnancy when compared to control group with $\mathrm{p}=0.02$. Increase in QT interval duration and decrease in $\mathrm{R}$ wave amplitude were also statistically highly significant associated in pregnancy (Table 1). 
Table 1: Comparison of ECG parameters between pregnant and non-pregnant women (total $n=120$ ).

\begin{tabular}{|c|c|c|c|}
\hline \multirow[b]{2}{*}{ Variables } & \multicolumn{2}{|c|}{ Mean \pm S.D } & \multirow[b]{2}{*}{ P value } \\
\hline & Third Trimester & Control & \\
\hline Age (years) & $24.75 \pm 3.51$ & $22.80 \pm 1.75$ & \\
\hline Heart rate (/min) & $82.08 \pm 9.58$ & $77.27 \pm 6.45$ & $0.002 * *$ \\
\hline PR Interval (sec) & $0.12 \pm 0.01$ & $0.14 \pm 0.01$ & $0.00 * * *$ \\
\hline QRS complex (sec) & $0.08 \pm 0.16$ & $\mathbf{0 . 0 8} \pm \mathbf{0 . 0 0}$ & $0.06 *$ \\
\hline QT interval (sec) & $0.36 \pm 0.03$ & $0.35 \pm 0.18$ & $0.03 * *$ \\
\hline QTc interval (sec) & $0.39 \pm 0.03$ & $0.37 \pm 0.02$ & $0.00 * * *$ \\
\hline QRS axis (degrees) & $36.68 \pm 21.44$ & $66.45 \pm 12.80$ & $0.00 * * *$ \\
\hline$P$ wave duration (sec) & $0.07 \pm 0.01$ & $0.07 \pm 0.01$ & $0.093 *$ \\
\hline P wave amplitude (mV) & $1.0 \pm 0.09$ & $1.03 \pm 0.18$ & $0.20 *$ \\
\hline $\mathbf{R}$ wave amplitude (mV) & $11.13 \pm 2.487$ & $12.15 \pm 2.09$ & $0.017 * *$ \\
\hline S wave amplitude (mV) & $9.70 \pm 3.228$ & $12.45 \pm 2.11$ & $0.00 * * *$ \\
\hline
\end{tabular}

Table 2. Comparison of $Q$ wave occurrence between two groups.

\begin{tabular}{|c|c|c|c|}
\hline Lead & ThirdTM & Control & Chi-Square test \\
\hline & N (\%) & N (\%) & P value \\
\hline I & 11 (18.30) & 3 (5.00) & $0.02 * *$ \\
\hline II & $18(30.00)$ & $6(10.00)$ & $0.00 * * *$ \\
\hline III & $21(35.00)$ & 7 (11.70) & $0.00 * * *$ \\
\hline aVR & - & - & - \\
\hline aVL & $11(18.30)$ & $0(\mathbf{0 . 0 0})$ & $0.00 * * *$ \\
\hline aVF & $12(20.00)$ & $6(10.00)$ & $0.12 *$ \\
\hline V1 & - & - & - \\
\hline V2 & - & - & - \\
\hline V3 & $2(3.30)$ & - & $0.15 *$ \\
\hline V4 & $6(10.00)$ & $3(5.00)$ & $0.29 \%$ \\
\hline V5 & $8(13.30)$ & $7(11.70)$ & $0.78 *$ \\
\hline V6 & 11(18.30) & $11(18.3)$ & $1.00 *$ \\
\hline
\end{tabular}

The results also showed that the increase number of Q wave appeared in 3rd trimester pregnancy when compared to the control group and was statistically highly significant in lead II, III, and lead avL and statistically significant in lead I.. (Table 2)

Regarding the $\mathrm{T}$ wave abnormalities seen in pregnancy, statistically highly significant association of occurrence of flat or inverted $\mathrm{T}$ waves were seen in $3^{\text {rd }}$ trimester pregnant women when compared to the control especially in lead III, aVF and anterior chest leads. The flat $\mathrm{T}$ waves were more in lead III, $\mathrm{V}_{3}$ and $\mathrm{V}_{4}$ whereas inverted $\mathrm{T}$ waves were more in other abnormal leads.(Table 3 )

There was no statistically significant association of ST segment depression with $3^{\text {rd }}$ trimester pregnancy compared with control. (Table 4) 
Table 3. Comparison of T-wave abnormalities between two groups.

\begin{tabular}{|c|c|c|c|c|c|c|c|}
\hline Lead & & Third T & & & Control & & Chi-square test \\
\hline & Flat & Inverted & Total & Flat & Inverted & Total & P value \\
\hline & $\mathbf{N}(\%)$ & N (\%) & N (\%) & N (\%) & N (\%) & N (\%) & \\
\hline I & - & - & - & - & - & - & - \\
\hline II & - & - & - & - & - & - & - \\
\hline III & $30(50)$ & $26(43.3)$ & $56(93.3)$ & $4(6.7)$ & 8(13.3) & $12(20)$ & $0.00^{* * * *}$ \\
\hline aVR & - & - & - & - & - & - & - \\
\hline $\mathbf{a V L}$ & - & - & - & - & - & - & - \\
\hline aVF & $8(13.3)$ & - & $8(13.3)$ & - & - & - & $0.00 * * *$ \\
\hline V1 & 3(5) & $53(88.3)$ & $56(93.3)$ & - & $43(71.7)$ & $43(71.7)$ & $0.00 * * *$ \\
\hline V2 & $4(6.7)$ & $36(60)$ & $40(66.7)$ & - & $2(3.3)$ & $2(3.3)$ & $0.00^{* * * *}$ \\
\hline V3 & $18(30)$ & $6(10)$ & $24(40)$ & - & - & - & $0.00^{* * * *}$ \\
\hline V4 & $8(13.3)$ & $1(1.7)$ & $9(15)$ & - & - & - & $0.00 * * *$ \\
\hline V5 & - & - & - & - & - & - & - \\
\hline V6 & - & - & - & - & - & - & - \\
\hline
\end{tabular}

Table 4: Comparison of ST segment depression between two groups.

\begin{tabular}{llllll} 
Variable & Particulars & Third TM & Control & \multicolumn{2}{c}{ Chi-square test } \\
ST segment & ST depression & N (\%) & N (\%) & $\mathbf{x}^{2}$ & P value \\
& & $1(1.70)$ & - & 1.00 & $0.31^{*}$
\end{tabular}

\section{DISCUSSION}

ECG taken for the study between two groups and their comparison has indeed proven the physiological changes do occur in pregnancy. The changes being physiological are focused to adapt the growing necessity of the maternal and fetal body. The decrease in PR interval observed during pregnancy is due to shortening of $\mathrm{A}-\mathrm{V}$ conductance with respect to increase heart rate accompanied during pregnancy. Joseph et $\mathrm{al}^{7}$ and Nandini et $\mathrm{al}^{8}$ also concluded with similar results. The increase in heart rate during pregnancy has been linked with autonomic nervous system changes that produce alteration in cardiac autonomic modulation. Failure of these adaptations may result in pregnancy related complications. ${ }^{9}$ The increase in heart rate mainly during third trimester compensates for the fall in stroke volume resulting from caval compression. ${ }^{10}$

The significant increase in QT and QTc interval in pregnancy was also reported by Lechmanova et al. ${ }^{11}$ These changes were attributed to changed spatial arrangement of 
chest organs during pregnancy, changed electrical properties of the myocardium due to changed sympathetic and hormonal modulation (epinephrine, progesterone) of the electrical heart activity during pregnancy.

The significant deviation of mean QRS frontal axis towards left in pregnancy was also reported by study conducted in Nigeria by Iwobi et $\mathrm{al}^{12}$ and in study of Singh AD et al. ${ }^{13}$ The rising position of diaphragm during pregnancy, ${ }^{13}$ alters the position of the heart. With this and increase in left ventricular size along with mass and increased volume ${ }^{8}$ results in shifting of QRS axis towards left.

The increase occurrence of $Q$ waves may be due to altered position of heart. ${ }^{13}$ The result was consistent with the study of Veille et al who reported to have occurrence of $\mathrm{Q}$ waves in lead II, III and aVF in late pregnancy. ${ }^{14}$ Similar finding of definite $Q$ wave in $23 \%$ pregnant women in lead III was reported by Burch et al. ${ }^{15} \mathrm{~T}$ wave abnormalities including both inverted and flat $\mathrm{T}$ waves were of low amplitudes. These findings were in parallel with Mishra et al who reported $70 \% \mathrm{~T}$ wave inversion in lead III and stated abnormal $\mathrm{T}$ waves can be in almost all chest leads during normal pregnancy. ${ }^{16}$ Similar results were reported by Wallace et al and Veille et al in their study. ${ }^{17,14}$ These findings may be due to temporary increased work load on heart due to increased blood volume during pregnancy which may cause a temporary ischemia thus representing inverted T waves. ${ }^{16}$ The decrease in amplitude of $\mathrm{R}$ and $\mathrm{S}$ waves coincides with the result of Edemeka et al who reported that the amplitudes of different waves to be decreased in pregnant than in non-pregnant group. ${ }^{18}$

\section{CONCLUSION}

The study has proven that the ECG parameters do alter during pregnancy. These parameters should be considered with caution so as not to diagnose falsely or fail to diagnose the condition behind these changes at heart. Though these changes in the electrocardiographic parameters in this study were formulated by comparing the pregnant and non-pregnant group, the result would have been more idealized if the electrocardiograms in the same group of individuals were compared before and during the pregnancy. Besides the attempt of making the pregnant group relaxed, the undergoing anxiety or stress could have made these changes in the electrocardiograms to some extent. However, the fact that cannot be denied is that the cardiovascular changes in the maternal body do occur and so does the electrocardiographic parameters.

\section{REFERENCES}

1. Boyle DM, Jones RLL. The electrocardiographic ST segment in normal pregnancy. J Obstet Gynecol Br CWlth 1966;73:986-7.

2. Dawn CS. Maternal physiology during pregnancy. In: Textbook of Obstetrics and Neonatology. 16th ed. Calcutta: Dawn books; 2003.

3. Ozmen N, Cebeci BS, Yiginer O, Muhcu M, Kardesoglu E and Dincturk M. P- wave dispersion is increased in pregnancy due to shortening of minimum duration of $\mathrm{p}$ : Does this have any clinical significance? J 
International medical research 2006;34:468-74.

4. Oakeley C, Warnes CA. Physiological changes in pregnancy. J Obstet Gynaecol India 1968;8:34-8.

5. Williams L, Wilkins. The heart and pregnancy. In: Text book of cardiovascular medicine. 2nd ed. USA: A wolters Kluwer Company; 2004. p.736.

6. Wagner GS. Interpretation of the normal electrocardiogram. In: Marriott's practical electrocardiography. 9th ed. New Delhi: B.I. Wavery; 1996.p.50.

7. Carruth JE, Mivis SB, Brogan DR, Wenger NK. The electrocardiogram in normal pregnancy. Am Heart J 1981;102:1075-8.

8. Nandini B, Shiva M. Shortening of PR Interval in different trimesters of pregnancy-A cross sectional study. International Journal of Biomedical and Advance Research 2011;2(11):422-6.

9. Stein PK, Hagley MT, Cole PL, Domitrovicn PP, Kleigner RE, Rottman JN. Changes in $24 \mathrm{hrs}$ heart rate variability during normal pregnancy. Am J Obstet Gynecol 1999;180(4):978-85.

10. Julian DG, Wenger NK. Heart disease and heart surgery during pregnancy. In: women and heart disease. United Kingdom; 2000.p. 196.

11. Lechmanova M, Kittnar O, Mleek M, Kolarick J, Parizek A. QT dispersion and T loop morphology in late pregnancy and after delivery. Physiol Res 2002;5:121-9.

12. Iwobi NN, Dapper DV. QRS axis deviation in Nigerian women during normal pregnancy. West Afr J Med 2002;21(3):241-3.

13. Singh AD, Devi L, Singh L, Devi R, Singh J. Electrocardiographic findings at term, labour and immediate postpartum. J Obstet \& Gynecol of India 1986;36:316-9.

14. Veille JC, Kitzman DW, Bacevice AE. Effects of pregnancy on the electrocardiogram in healthy subjects during strenuous exercise. Am J Obstet Gynecol 1996;175(5):1360-4.

15. Burch GE, Abildskov JA, Cronvich JA. The spatial vector cardiogram and mean ventricular gradient in normal pregnant women. Circulation 1954;9:381-7.

16. Mishra J, Dutta B, Ganguly D. Electrocardiographic study in pregnant women in normal and toxemia of pregnancy. J Obstet Gynecol India 1986;36:635-8.

17. Wallace J, Katz LM, Langendorf R, Buxbaum H. Electrocardiogram in toxemias of pregnancy. Arch Int Med 1946;77:405-19.

18. Edemeka DB, Ekong MN. The electrocardiogram of pregnant Nigerian women. West Afr J Med 1995;14(4): 227-32. 